\title{
Notes de la rédaction sur les comptes-rendus
}

\section{Daniel Pichot et Jean Le Bihan}

\section{Q OpenEdition}

\section{Journals}

\section{Édition électronique}

URL : http://journals.openedition.org/abpo/2185

DOI : $10.4000 /$ abpo. 2185

ISBN : 978-2-7535-1841-4

ISSN : 2108-6443

\section{Éditeur}

Presses universitaires de Rennes

\section{Édition imprimée}

Date de publication : 30 décembre 2011

Pagination : 127-163

ISBN : 978-2-7535-1839-1

ISSN : 0399-0826

\section{Référence électronique}

Daniel Pichot et Jean Le Bihan, "Notes de la rédaction sur les comptes-rendus », Annales de Bretagne et des Pays de l'Ouest [En ligne], 118-4 | 2011, mis en ligne le 30 décembre 2011, consulté le 23 septembre 2020. URL : http://journals.openedition.org/abpo/2185 ; DOI : https://doi.org/10.4000/ abpo. 2185

Ce document a été généré automatiquement le 23 septembre 2020.

(C) Presses universitaires de Rennes 


\title{
Notes de la rédaction sur les comptes-rendus
}

\author{
Daniel Pichot et Jean Le Bihan
}

\section{NOTE DE L'ÉDITEUR}

Rendre compte de la diversité des recherches menées par les historiens du grand Ouest constitue assurément l'une des missions majeures des ABPO. C'est pourquoi le comité de rédaction a décidé l'an dernier d'étoffer cette rubrique. Le nombre de comptes rendus sera désormais significativement accru, mais en contrepartie, vu la masse des publications, les recensions ne porteront plus essentiellement que sur des ouvrages traitant - en totalité ou partiellement - de l'histoire de l'Ouest. Refléter aussi fidèlement que possible la recherche historique en train de se faire exige bien entendu le concours de tous, aussi les lecteurs sont-ils invités à nous signaler les ouvrages qui méritent selon eux d'être recensés, étant entendu que, malgré notre vigilance, bien des travaux dignes d'intérêt continueront de nous échapper. Tout lecteur peut même se proposer pour rédiger un compte-rendu, mais nous lui demandons dans ce cas de nous contacter préalablement, ne serait-ce que pour prévenir le risque de doublon. Puisse cette nouvelle politique rendre service à tous. 